\title{
OP-29 MEANS TESTING AND USER CHARGES IN HEALTH CARE: MEANS TESTING IN TERTIARY LEVEL PUBLIC HOSPITALS IN KERALA
}

SK Godwin. Government College for Women, Trivandrum (Kerala), India

\subsection{6/bmjgh-2016-EPHPabstracts.29}

Background Developing country health systems are characterised by under-funded healthcare provision, distorted priorities in resource allocation, weak governance and regulatory structures, and sub-optimal policy interventions. Health sector reforms had been a long pending demand from both within the health system and outside. The central approach of the reforms was two-fold: increasing efficiency in resource use, and serving equity by excluding high-income groups and including only the poor in publicly-funded action. Reforms included revised health financing, insurance, and targeting low-income segments of the population.

Targeting assumes a development approach of cost-effective poverty reduction rather than an administrative enterprise. Means testing is often suggested as a mechanism to shield the poorest under cost-recovery programme by granting fee waivers for individuals who are less capable of paying for goods and services. Providing a safety net for the poorest while permitting fees to be collected from those with ability to pay, means testing could be an essential tool to promote fee collection and equity simultaneously.

Methods This study tries to understand the existing system of means testing in public hospitals in Kerala, India, by enquiring on the nature and institutional framework for means testing as well as the characteristics of the major criteria used to assess means testing. The study selected five major public hospitals in the state. These are specialised institutions offering advanced healthcare interventions available otherwise only in specialty private health institutions. A uniform schedule was circulated 
across selected healthcare institutions inquiring on basic details of the hospital, methods used for means testing, reliance on own sources of revenue, and magnitude and proportion of price discrimination.

Findings The selected hospitals charge fees depending on their stature, legislative mandate and autonomy. There exist, primarily, about three categories of patients in these hospitals on the basis of charging fees. They include full paying category, partially paying category and fully exempted categories in these institutions. On average, in the year 2009-10, about $42 \%$ of patients paid full fees, while $20 \%$ paid partial charges and $38 \%$ were exempted from any payment. Though all institutions under study were public, institutions under the provincial government use indicators called Above-Poverty-Line (APL) and Below-Poverty-Line (BPL). All institutions have a defined user fee policy suggesting user fees as essential in tertiary care as it increases the compliance of medicines, as making patients and providers responsible for the use/misuse, and as ensuring economic sustainability. All institutions have a graded pricing system with multiple layers, except in provincial government run institutions where only the two mentioned categories exist. Some institutions have five categories. Institutions under state government have long waiting lists, extending more than 90 days for many elective interventions. The directly operated state-owned institutions do not charge anything for emergency care for both poor and non-poor.

Discussion Though all institutions under study have a declared policy of non-denial of treatment in case of inability to pay, the realisation of this policy is questionable. The institutions assume an independent and objective assessment of the patient by an identifying official, which is a highly risky assumption in lowincome settings where a well functioning governance system is non-existent. The pricing of services, it is stated, is not based on the cost incurred, but rather randomly done. Though prices in the studied public hospitals are significantly below these of their private counterparts, a costing exercise of major services would be useful for reduction of inefficiencies, expansion of certain services, and defining price pattern of different services.

Provision of discretion to the local authority in the hospital has some advantages as it ensures that hardly anyone in genuine need of health care is denied. However, contemporary evidence suggests, if the exemption mechanisms are implemented under weak governance system as in most low-income settings, it is likely to aggravate the type II error in targeting (excluding a person who should have been provided benefits). One of the feasible options is to have a broader classification of above and below poverty line population so that a higher degree of selfselection would be achieved and administrative cost and corruption reduced.

A major limitation of our study is that it reports the outcomes of only a few major institutions and generalisation is limited to the extent. Secondly, a patient-oriented analysis is essential if we are to identify whether appropriate targeting of benefits happened or otherwise.

No conflict of interest. 